\title{
The Impact of Diacetylmorphine on Hypothalamic-Pituitary-Adrenal Axis Activity and Heroin Craving in Heroin Dependence
}

\author{
Hana Gerber a, b Stefan J. Borgwardt ${ }^{a}$ Otto Schmid ${ }^{a} \quad$ Urs Gerhard $^{a}$ \\ Wolfgang Joechle ${ }^{c}$ Anita Riecher-Rössler ${ }^{a}$ Gerhard A. Wiesbeck ${ }^{a}$ Marc Walter $^{a}$ \\ a Psychiatric Hospital, University of Basel, ${ }^{b}$ Department of Psychology, University of Basel, and \\ 'Laboratory Medicine, University Hospital Basel, Basel, Switzerland
}

\section{Key Words}

Adrenocorticotropic hormone $\cdot$ Cortisol $\cdot$ Craving $\cdot$

Diacetylmorphine $\cdot$ Heroin-assisted treatment $\cdot$

Hypothalamic-pituitary-adrenal axis · Opioid dependence • Stress

\begin{abstract}
Background/Aim: Heroin dependence is a chronic relapsing disorder characterized by the compulsion to seek and use heroin. Stress and craving are seen as key factors for heroin use. Moreover, altered hypothalamic-pituitary-adrenal (HPA) axis function has been frequently reported. However, the acute effects of diacetylmorphine (DAM) on HPA axis activity and craving have not been investigated in a controlled study. The present randomized controlled study examined whether DAM administration differs from placebo (saline) administration with regard to HPA axis response and heroin craving. Methods: In a crossover experiment, 28 DAM-maintained heroin-dependent patients were first injected with DAM and then saline, or the converse. Plasma adrenocorticotropic hormone (ACTH) and cortisol in saliva and serum were measured at baseline and 20 and $60 \mathrm{~min}$ after both injections. Heroin craving was measured at baseline and $60 \mathrm{~min}$ after
\end{abstract}

both injections, by means of the Heroin Craving Questionnaire. Results: Compared to saline, DAM administration induced a significant decrease in plasma ACTH $(p<0.01)$, serum cortisol $(p<0.0001)$ and saliva cortisol $(p<0.01)$, as well as in craving $(p<0.0001)$, over time. Conclusion: Since acute DAM administration suppresses the stress response, DAMassisted treatment may be an effective alternative to methadone maintenance in stress-sensitive heroin-dependent patients.

Copyright $\odot 2012$ S. Karger AG, Basel

\section{Introduction}

Opioid dependence is a chronic relapsing brain disorder characterized by compulsive seeking and use of opioids despite the negative consequences [1]. Drug-related cues, stress or negative mood are associated with craving [2-5]. Several previous studies have shown the relevance of stress and hypothalamic-pituitary-adrenal (HPA) axis dysfunction in substance use disorders [6-11].

The first findings on the suppression of adrenocortical functions in opiate dependence were reported by Eisenman et al. $[12,13]$ in the 1950s and 1960s in Lexington,

\section{KARGER}

Fax +41613061234 E-Mail karger@karger.ch www.karger.com (c) 2012 S. Karger AG, Basel

$1022-6877 / 12 / 0183-0116 \$ 38.00 / 0$

Accessible online at:

www.karger.com/ear
Hana Gerber, lic. phil.

Universitäre Psychiatrische Kliniken (UPK), Abhängigkeitserkrankungen

Wilhelm Klein-Strasse 27

$\mathrm{CH}-4012$ Basel (Switzerland)

Tel. +41 6132556 86, E-Mail hana.gerber@ upkbs.ch 
Ky., USA. They found reduced urinary levels of 17-ketosteroids [12] and reduced plasma levels of 17-hydroxycorticosteroids [13] during a period of addiction in men, in comparison to a phase of nonaddiction. Moreover, these levels increased upon discontinuation of morphine. After detoxification, these levels returned to the preaddiction range $[12,13]$, indicating that stress hormone secretion was depressed during opioid addiction and elevated during withdrawal. Further research has shown that opioids administered during surgery suppress HPA axis activity $[14,15]$. Furthermore, heroin-dependent subjects exhibited lower plasma levels of adrenocorticotropic hormone (ACTH) and cortisol when compared with healthy individuals $[14,16]$, thus providing further evidence that HPA axis activity is suppressed during active opioid dependence. On the other hand, recent studies suggest that substance use disorders are associated with elevated cortisol levels and depressive symptoms [17]. The increased HPA axis activity might constitute a vulnerability to the development of substance use disorders and relapse, and this relationship seems to be influenced by stressful life experiences $[18,19]$.

The altered HPA axis function in substance use disorders is related to early life stress [20, 21]. Patients reporting childhood trauma showed increased cortisol and decreased ACTH concentrations during withdrawal, which possibly reflect a persistent blunting of the HPA axis function as well as its hypersensitive reaction to acute stress in traumatized, alcohol-dependent patients [20]. Moreover, higher cortisol and ACTH plasma levels were found in abstinent heroin- and cocaine-dependent patients in comparison to healthy control subjects without a history of illicit drug use and childhood trauma [21].

Opioid withdrawal is associated with increased stress hormone levels [22]. Research on opioid antagonists (e.g. naloxone) further supports this finding [23, 24]. However, elevated stress reactivity was also found in currently abstinent, formerly heroin-dependent individuals not under opioid maintenance, which could be related to heightened craving and relapse [25-27]. Opioid agonists, on the other hand, are associated with a reduction in stress hormone secretion $[28,29]$. In preliminary studies, our group also found that opioids suppress cortisol concentrations in heroin-dependent patients and reduce craving after methadone administration [30, 31].

Although previous findings have consistently shown that HPA axis function is modified in heroin dependence and that opioids suppress stress hormone release, there have been few experimental studies and these have gener- ally focused on the effects of methadone [28, 29]. However, methadone maintenance treatment (MMT) is not the only treatment for severe heroin dependence, as heroin-assisted treatment (HAT), involving the prescription of pharmaceutical heroin (diacetylmorphine, DAM), medical attendance and psychosocial support, is also effective [32]. Chronic heroin-dependent patients who initially do not benefit sufficiently from MMT and abstinence-oriented (drug-free) treatments respond well to treatment with DAM and improve significantly in terms of mental and physical health and psychosocial functioning, mainly assessed as reduction in crime and concurrent use of illegal substances [33-39].

The present randomized controlled trial examined HPA axis function in opioid dependence after DAM administration. Our aim was to investigate the acute effects of DAM on HPA axis activity, subjective craving and withdrawal symptoms in chronic heroin-dependent patients. We hypothesized that DAM would suppress ACTH and cortisol concentrations and heroin craving, in contrast to the increases in these parameters observed during withdrawal.

\section{Materials and Methods}

\section{Study Sample}

Twenty-eight patients $(67.9 \%$ men, $\mathrm{n}=19)$ were recruited from patients at the Division of Substance Use Disorders of the Psychiatric Hospital of the University of Basel. They were aged 23-58 years (mean age 41.3 years, SD 6.6), met the DSM-IV diagnostic criteria for opioid dependence and had been in HAT for a mean period of 6.7 years (SD 4.5). Exclusion criteria included a positive breath alcohol test and a history of significant medical problems or major mental disorders (other than substance use and personality disorders). All patients received written information on the examination protocol and gave their written consent. The study was approved by the local ethics committee.

\section{Procedure}

The present study is a part of a randomized controlled clinical trial. It has been registered on the website http://clinicaltrials.gov (ID NCT01174927). All patients were submitted to both conditions in a crossover design. The sequence of the injected substances [DAM and saline $(\mathrm{NaCl})$ as placebo] was randomized. One group $(n=14)$ first received their daily dose of DAM before the beginning of the experiment, whereas the second group $(\mathrm{n}=14)$ first received placebo $(\mathrm{NaCl})$. The patients were blinded to the substance. DAM was provided by the Swiss Federal Office of Public Health in the form of the hydrochloride salt. This was dissolved in water (1:9) on site and aspirated into a syringe, which was adapted to the evacuated infusion system. Patients of the second group were given their daily dose of DAM immediately after the experiment. The test period lasted approximately $2.5 \mathrm{~h}$, including stressful stimuli during a functional magnetic resonance imaging 
Table 1. Sociodemographic and diagnostic characteristics of the study sample $(\mathrm{n}=28)$

\begin{tabular}{lcr}
\hline Characteristic & Mean & SD \\
\hline Age, years & 41.3 & 6.6 \\
Male gender & $19(67.9)$ & \\
Education, years & 10.4 & 2.5 \\
In relationship & $9(32.1)$ & \\
Employed & $11(39.3)$ & \\
Disability & $9(32.1)$ & \\
Doses of DAM, mg/day & 318.6 & 131.7 \\
Methadone maintenance & $13(46.4)$ & \\
Doses of methadone, mg/day & 13.4 & 17.4 \\
Duration of dependence, years & 20.8 & 6.6 \\
Age at first-time heroin use, years & 19.0 & 3.4 \\
Duration of opioid maintenance, years & 6.7 & 4.5 \\
Substance abuse & & \\
$\quad$ Tobacco & $28(100.0)$ & \\
$\quad$ Number of cigarettes/day & 21.0 & 9.1 \\
$\quad$ Cocaine & $15(53.6)$ & \\
$\quad$ Cannabis & $8(28.6)$ & \\
\hline
\end{tabular}

Values in parentheses represent percentages.

(fMRI) examination. One week later, the patients completed the alternative treatment, with the opposite sequence of substance injections. Both sessions were performed in the morning.

\section{Biochemical Measurements}

$\mathrm{ACTH}$ and cortisol were taken as measures of the stress response. Samples were collected at baseline (at least $1 \mathrm{~h}$ after awakening, 7.30 a.m.) and $20 \mathrm{~min}(9.00$ a.m.) and $60 \mathrm{~min}$ after substance administration (10.30 a.m.). Salivary cortisol was analyzed with a time-resolved immunoassay with fluorescence detection, as described elsewhere [30]. Total cortisol concentrations were measured in serum with the Immulite 2000 cortisol test (Siemens, Germany). ACTH was measured in EDTA plasma with the ACTH Immulite test (Siemens). Interassay and intra-assay coefficients of variance were below $10 \%$ for all analyses.

\section{Psychological Measurements}

Psychological data were collected at the beginning and the end of the experiment. The Heroin Craving Questionnaire (HCQ) [40] was used to measure heroin craving. A reliability of $\alpha=0.94$ was calculated. The corresponding scale contains 9 items and measures the desire to use heroin.

In order to detect possible placebo effects, $3 \mathrm{~min}$ after the substance administration the patients were asked which substance they believed they had received, i.e. DAM or placebo. Additionally, both subjective drug effects and withdrawal symptoms were measured using a visual analogue scale $(0=$ none, $10=$ very strong $)$.

\section{Statistical Analyses}

For each of the outcome variables (plasma ACTH, serum cortisol, salivary cortisol concentrations), a two-factorial repeatedmeasures analysis of variance (ANOVA) was calculated, with two within-subject substances (DAM/placebo) and the between-subjects group membership (sequence of the administered substances). Cocaine use was included in the analyses as a covariate. In order to take the large range of individual baseline hormone levels into account, ANOVAs were carried out with the differences between the baseline and post-trial measurements (i.e. before and $60 \mathrm{~min}$ after substance injection). To evaluate the stress hormone changes across the 3 measurement points under both conditions (baseline and 20 and 60 min after substance injection), pairwise contrasts of the hormone levels were calculated. For the non-normally distributed variables, a nonparametric analysis (Friedman's ANOVA with Wilcoxon signed-rank post hoc tests) was calculated. The Bonferroni correction was used to correct for the $\alpha$-error accumulation.

Psychometric data (HCQ scores and subjective rating of drug effects and withdrawal symptoms) were analyzed with the t test and, where appropriate, with a nonparametric test (Wilcoxon signed-rank test) for dependent samples.

All analyses were computed with the statistical program SPSS 19.0. Graphs were created with SigmaPlot 11.0. The two-tailed significance level was set to $\mathrm{p}<0.05$.

\section{Results}

\section{Demographic and Clinical Variables}

As shown in table 1,8 patients $(28.6 \%)$ tested positive for cannabis and 15 patients (53.6\%) for cocaine at one or both measurements. No significant differences were observed between the two groups in terms of diagnostic and sociodemographic variables $(\mathrm{p}>0.05)$. Table 1 gives an overview of the characteristics of our patient sample.

\section{Drug Effects, Withdrawal Symptoms and Heroin Craving}

As expected, significantly more drug effects and fewer withdrawal symptoms were reported after injection of DAM than with placebo $(\mathrm{p}<0.0001)$. Only one placebo effect was observed, as one patient rated $\mathrm{NaCl}$ as DAM.

No significant differences between HCQ scores at baseline (i.e. before any substance administration) were found ( $p>0.05$ ). Before and after placebo injection, HCQ scores did not differ significantly either ( $\mathrm{p}>0.05)$. However, after DAM administration, craving dropped significantly over time $(t=5.19$, degrees of freedom $=27 ; \mathrm{p}<$ 0.0001). Compared with placebo, significantly lower craving was reported at the end of the sequence when patients received DAM $(t=-5.63$, degrees of freedom $=27$; $\mathrm{p}<0.0001$ ) (fig. 1).

At the end of the experiment (i.e. 60 min after substance injection), HCQ scores were significantly associated with changes in ACTH secretion. As expected, major heroin craving was positively related with increased 


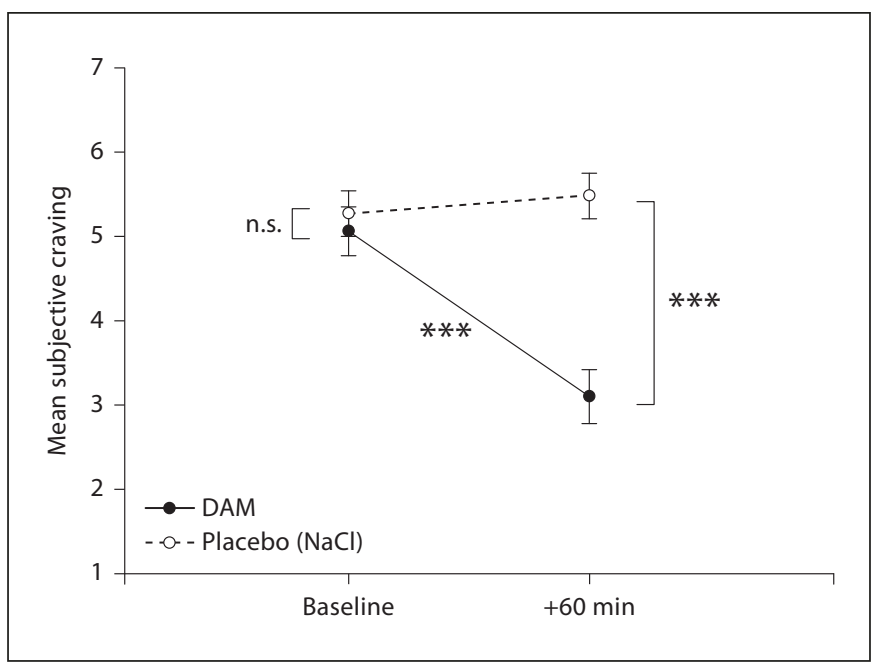

Fig. 1. Patients' subjective craving (Desire to Use Heroin scale, HCQ) before and after substance administration. Means and standard errors are displayed. ${ }^{* *} \mathrm{p}<0.0001$, n.s. $=$ not significant.

ACTH concentrations when patients received placebo $(r=0.30 ; p<0.05)$. No other significant correlation was found between the subjective craving scores and the hormonal stress response $(\mathrm{p}>0.05)$.

\section{HPA Axis Activity}

DAM significantly suppressed hormone concentrations, as follows: ACTH, $\mathrm{F}(1,25)=8.54, \mathrm{p}=0.007$; cortisol serum, $\mathrm{F}(1,25)=30.69, \mathrm{p}<0.0001$, and cortisol saliva, $\mathrm{F}$ $(1,25)=11.83, p=0.002$. No significant effects on the hormone levels of cocaine use or group membership were observed ( $\mathrm{p}>0.05)$ (table 2).

The pairwise comparisons of the hormone levels showed significant reductions in plasma ACTH, serum cortisol and saliva cortisol concentrations over time after DAM administration $(\mathrm{p}<0.0001)$. After placebo administration, only plasma ACTH increased significantly, between 20 and $60 \mathrm{~min}$ after the injection $(\mathrm{p}<0.01)$. Cortisol levels did not increase significantly after placebo injection ( $p>0.05)$. No significant differences between the baseline hormone levels were found ( $p>0.05$ ) (fig. 2-4).

\section{Discussion}

The present study examined the acute effects of DAM (pharmaceutical heroin) on HPA axis function and heroin craving in a controlled experimental setting. There

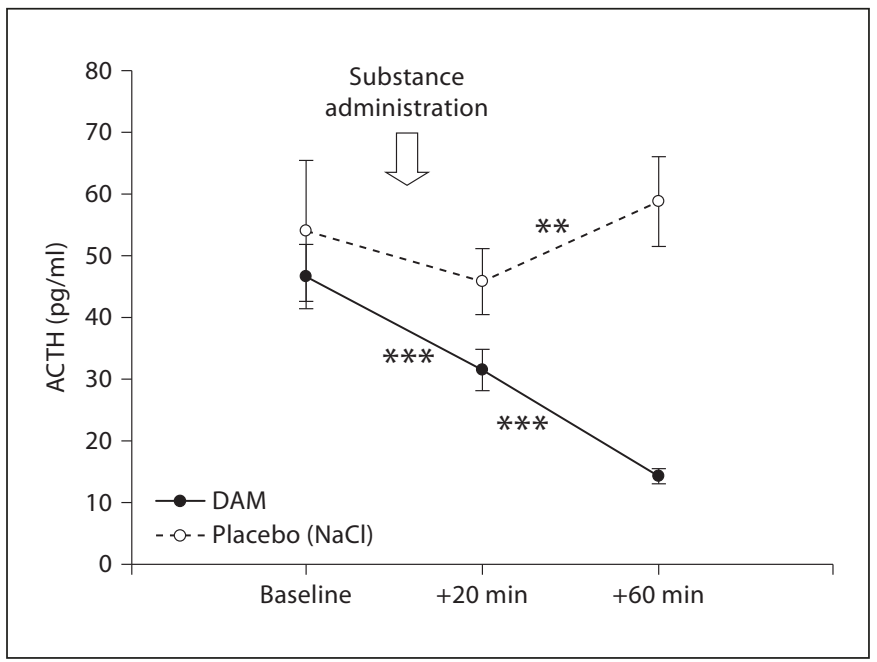

Fig. 2. ACTH concentration in DAM (heroin)-maintained patients after DAM (heroin) or placebo (saline) injection. Means and standard errors are displayed. ${ }^{* *} \mathrm{p}<0.01,{ }^{* *} \mathrm{p}<0.0001$.

were significant decreases in ACTH and cortisol concentrations and in HCQ scores with DAM in comparison to placebo, demonstrating that DAM suppressed HPA axis activity and reduced heroin craving in chronic heroindependent, DAM-maintained patients.

The suppressive effect of opioids in general [12-16] and of methadone in particular $[25,30]$ on stress hormone secretion and subjective craving has already been shown. Our recent uncontrolled study also found reduced cortisol concentrations in heroin-dependent patients after they had received DAM [31]. This has now been confirmed for the first time in a randomized, controlled, crossover study. There was no significant interaction between the injected substance and concurrent cocaine use or the sequence of administration, indicating that the suppression of the HPA axis is solely due to DAM administration, there is no significant carryover effect and cocaine abuse is irrelevant [41]. Our results thus confirm the attenuating effect of acute opioid administration on the HPA axis response. Further studies should investigate whether maintenance treatment with DAM also normalizes diurnal stress hormone secretion in opioiddependent patients.

In previous studies, opioid withdrawal was associated with increased stress hormone secretion [22-24]. However, in contrast to the highly significant continuous decline in the hormone concentrations after DAM administration, the increase in the hormone levels after placebo 


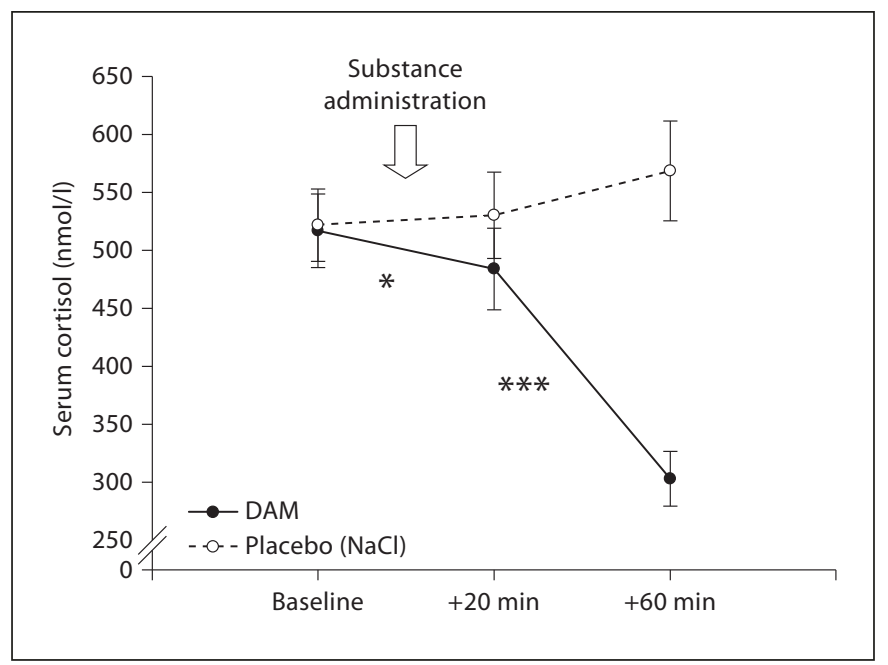

Fig. 3. Serum cortisol concentration in DAM (heroin)-maintained patients after DAM (heroin) or placebo (saline) injection. Means and standard errors are displayed. ${ }^{*} \mathrm{p}<0.05,{ }^{* *} \mathrm{p}<$ 0.0001 .

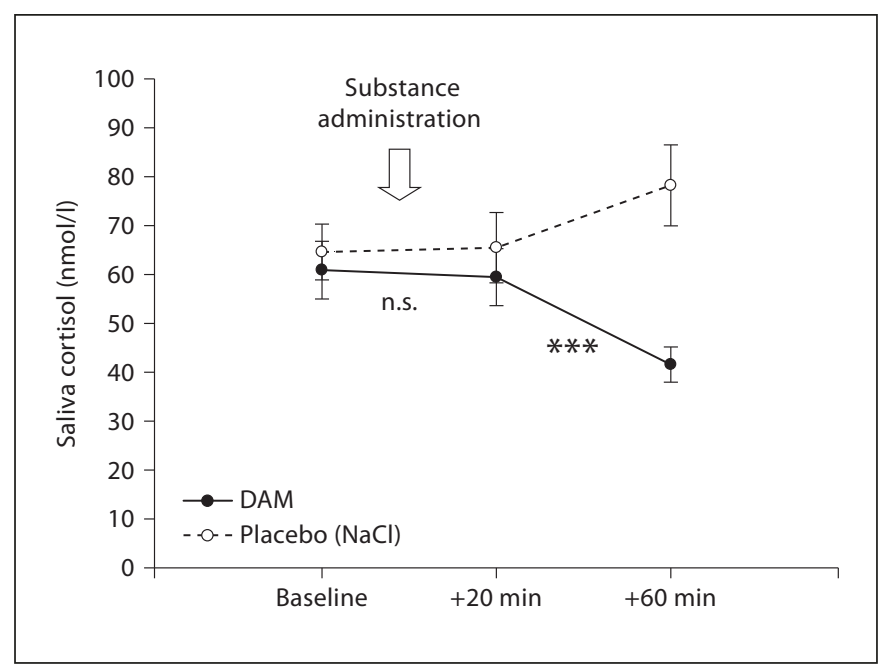

Fig. 4. Saliva cortisol concentration in DAM (heroin)-maintained patients after DAM (heroin) or placebo (saline) injection. Means and standard errors are displayed. ${ }^{* *} \mathrm{p}<0.0001$, n.s. $=$ not significant.

Table 2. ANOVA for the effects of the substance (DAM) on stress hormone levels and the interactions between substance and cocaine abuse and between substance and group membership

\begin{tabular}{|c|c|c|c|c|c|}
\hline & SS & d.f. & MS & $\mathrm{F}$ & $\mathrm{p}$ value \\
\hline \multicolumn{6}{|l|}{ ACTH } \\
\hline Substance & $12,696.98$ & 1 & $12,696.98$ & 8.54 & 0.007 \\
\hline Substance $\times$ cocaine abuse & 681.45 & 1 & 681.45 & 0.46 & 0.505 \\
\hline Substance $\times$ group & 960.19 & 1 & 960.19 & 0.65 & 0.429 \\
\hline Error (substance) & $37,151.20$ & 25 & $1,486.05$ & & \\
\hline \multicolumn{6}{|l|}{ Cortisol serum } \\
\hline Substance & $515,684.12$ & 1 & $515,684.12$ & 30.69 & 0.000 \\
\hline Substance $\times$ cocaine abuse & $7,042.94$ & 1 & $7,042.94$ & 0.42 & 0.523 \\
\hline Substance $\times$ group & $2,352.60$ & 1 & $2,352.60$ & 0.14 & 0.711 \\
\hline Error (substance) & $420,064.11$ & 25 & $16,802.56$ & & \\
\hline \multicolumn{6}{|l|}{ Cortisol saliva } \\
\hline Substance & $7,131.07$ & 1 & $7,131.07$ & 11.83 & 0.002 \\
\hline Substance $\times$ cocaine abuse & 3.76 & 1 & 3.76 & 0.01 & 0.938 \\
\hline Substance $\times$ group & $1,916.02$ & 1 & $1,916.02$ & 3.18 & 0.087 \\
\hline Error (substance) & $15,070.16$ & 25 & 602.81 & & \\
\hline
\end{tabular}

SS = Sum of squares; d.f. $=$ degrees of freedom; MS = mean square; $\times=$ interaction.

in our study was slight or nonsignificant. Only ACTH levels increased significantly between 20 and $60 \mathrm{~min}$ after placebo injection, but the main time effect was nonsignificant as well. Hence, our findings do not support the idea that opioid withdrawal is associated with activation of the HPA axis. These results can possibly be explained by the patients' long-standing heroin-assisted treatment (HAT). Moreover, patients in both groups knew that they would receive their daily DAM dose at the end of the experiment at the latest. Although they reported withdrawal symptoms, they may not have experienced intense somatic withdrawal. Wisniewski et al. [17] found elevated 
basal cortisol levels in active drug users, which might reflect withdrawal symptoms during the study as well as the combination of heroin and cocaine commonly used by illicit drug users. Therefore, in our study the regularity of DAM administration and its availability, as well as other psychological factors associated with the HAT, including psychosocial support, may have been relevant factors influencing the patients' stress response, resulting in relative stability of stress hormone secretion during the experiment, even in the placebo condition. The association between opioid withdrawal and HPA axis activity in heroin-dependent patients should next be examined by including heroin-dependent individuals without opioid maintenance treatment.

The significant correlation between the craving scores and the changes in ACTH levels at the end of the experiment showed the relationship between the patients' subjective feeling and their endocrine response, suggesting that the greater the subjective withdrawal, the higher the stress hormone concentrations and vice versa. However, this relationship does not allow the conclusion that changes in the HPA response have a significant impact on the subjective experience of craving. Nevertheless, based on the consistent previous findings that opioid withdrawal is associated with increased stress hormone release [22-24], the elevated ACTH levels might be a possible explanation for the higher subjective craving scores.

The advantages of the present study are its randomized, controlled, crossover design and the adequate sample size, which allowed for the control of confounding variables and sequence effects. On the other hand, the stressful stimuli presented in the fMRI session were not a valid stress test (such as the Trier Social Stress Test [42]). However, performance tasks which could be unfavorably evaluated by others, as used here, constitute psychological stress, and the relevance of such tasks to increased cortisol and ACTH responses has already been shown [43]. Most notably, fMRI scanning has been demonstrated to be a stressful experience associated with elevated cortisol concentrations in healthy persons and depressive patients [44-46]. In substance use disorders, psychosocial stress is generally considered to be a predictive factor for relapse [19, 47, 48].

Several previous studies have established positive effects of DAM maintenance in heroin dependence in patients for whom MMT or abstinence-orientated (drugfree) therapy had been unsuccessful [32, 33, 35-39]. Despite the above-mentioned limitations, the present study supports the efficacy of HAT and provides potential evi- dence for clinical implications. MMT-resistant patients who seem to react strongly to stress may possibly profit in particular from DAM maintenance. Short-acting opioids (e.g. heroin) seem to lessen the heightened stress reactivity and desire for heroin, as observed in former heroin users without opioid maintenance treatment [25-27], and might thereby prevent relapse with its serious consequences. However, based on the intravenous administration of DAM, there is a greater risk of negative side effects in HAT (respiratory depression, epileptic seizure) [36, 38, 49]. Under medical supervision and with an adequate waiting period after DAM injection, such incidents can be avoided, so that the safety and efficacy of the treatment remain assured. In addition to the injectable form, oral administration as a tablet is possible [50].

HAT is an established treatment form for severe opioid dependence in Switzerland and the Netherlands [32]. For those chronic heroin-dependent patients who initially do not profit from other treatments, it is an effective alternative treatment and complements the therapeutic spectrum for opioid dependence [51]. Moreover, recent research has indicated the efficacy of HAT even in heroin-dependent patients with no previous maintenance experience [52]. A better understanding of the acute effects of DAM (heroin) would therefore promote the optimization of the treatment for chronic opioid dependence.

\section{Acknowledgements}

This study was funded by the Swiss National Science Foundation (32003B-127544) and the Freiwillige Akademische Gesellschaft, Basel, Switzerland.

References

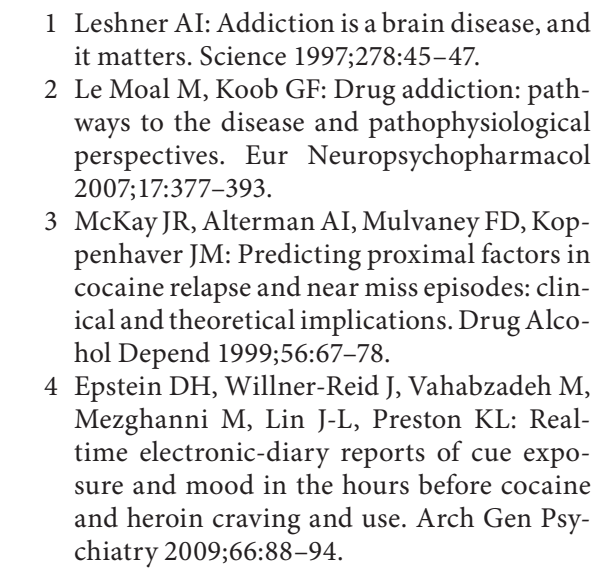

Eur Addict Res 2012;18:116-123 
$\checkmark 5$ Childress AR, Ehrman R, McLellan AT, MacRae J, Natale M, O’Brien CP: Can induced moods trigger drug related responses in opiate abuse patients? J Subst Abuse Treat 1994;11:17-23.

6 Koob GF, Le Moal M: Drug addiction, dysregulation of reward, and allostasis. Neuropsychopharmacology 2001;24:79-129.

$\checkmark 7$ Piazza PV, Le Moal M: The role of stress in drug self-administration. Trends Pharmacol Sci 1998;19:67-74.

$\checkmark 8$ Kiefer F, Wiedemann K: Neuroendocrine pathways of addictive behaviour. Addict Biol 2004;9:205-212.

$\checkmark 9$ Brown TT, Wisniewski AB, Dobs AS: Gonadal and adrenal abnormalities in drug users: cause or consequence of drug use behavior and poor health outcomes. Am J Infect Dis 2006;2:130-135.

$\checkmark 10$ Kreek MJ, LaForge KS, Butelman E: Pharmacotherapy of addictions. Nat Rev Drug Dis cov 2002; 1:710-726.

-11 Schluger JH, Bart G, Green M, Ho A, Kreek MJ: Corticotropin-releasing factor testing reveals a dose-dependent difference in methadone maintained versus control subjects. Neuropsychopharmacology 2003;28: 985-994.

$\checkmark 12$ Eisenman AJ, Fraser HF, Sloan J, Isbell H: Urinary 17-ketosteroids during a cycle of addiction to morphine. J Pharmacol Exp Ther 1958;124:305-311.

$\checkmark 13$ Eisenman AJ, Fraser HF, Brooks JW: Urinary excretion and plasma levels of 17-hydroxycorticosteroids during a cycle of addiction to morphine. J Pharmacol Exp Ther 1961;132: 226-231.

- 14 Facchinetti F, Volpe A, Farci G, Petraglia F, Porro CA, Barbieri G, Cioni A, Balestrieri A, Genazzani AR: Hypothalamus-pituitaryadrenal axis of heroin addicts. Drug Alcohol Depend 1985;15:361-366.

15 George JM, Reier CE, Lanese RR, Rower JM: Morphine anesthesia blocks cortisol and growth hormone response to surgical stress in humans. J Clin Endocrinol Metab 1974; 38:736-741

- 16 Ho WKK, Wen HL, Fung KP, Ng YH, Au KK, Ma L: Comparison of plasma hormonal levels between heroin-addicted and normal subjects. Clin Chim Acta 1977;75:415419.

$\checkmark 17$ Wisniewski AB, Brown TT, John M, Cofranceso J Jr, Golub ET, Ricketts EP, Wand G, Dobs AS: Cortisol levels and depression in men and women using heroin and cocaine. Psychoneuroendocrinology 2006;31: 250-255.

-18 Rao U, Hammen CL, Poland RE: Mechanism underlying the comorbidity between depressive and addictive disorders in adolescents: interactions between stress and HPA activity. Am J Psychiatry 2009;166:361-369.
19 Walter M, Gerhard U, Gerlach M, Weijers H-G, Boening J, Wiesbeck GA: Cortisol concentrations, stress-coping styles after withdrawal, and long-term abstinence in alcohol dependence. Addict Biol 2006;11:157162.

20 Schäfer I, Teske, L, Thüsing-Schulze J, Homann K, Reimer J, Haasen C, Hissbach J, Wiedemann K: Impact of childhood trauma on hypothalamus-pituitary-adrenal axis activity in alcohol-dependent patients. Eur Addict Res 2010;16:108-114.

21 Gerra G, Leonardi C, Cortese E, Zaimovic A, Dell'Agnello G, Manfredini M, Somaini L, Petracca F, Caretti V, Baroni C, Donnini $\mathrm{C}$ : Adrenocorticotropic hormone and cortisol plasma levels directly correlate with childhood neglect and depression measures in addicted patients. Addict Biol 2008;13. 95-104.

22 Camí J, Gilabert M, San L, De La Torre R Hypercortisolism after opioid discontinuation in rapid detoxification of heroin addicts. Br J Addict 1992;87:1145-1151.

23 Culpepper-Morgan JA, Kreek MJ: Hypothalamic-pituitary-adrenal axis hypersensitivity to naloxone in opioid dependence: a case of naloxone-induced withdrawal. Metabolism 1997;46:130-134

24 Volavka J, Cho D, Mallya A, Baumann J: Naloxone increases ACTH and cortisol levels in man. N Engl J Med 1979;300:1056-1057.

25 Kreek MJ: Opiates, opioids and addiction. Mol Psychiatry 1996;1:232-254.

26 Kreek MJ, Koob GF: Drug dependence: stress and dysregulation of brain reward pathways. Drug Alcohol Depend 1998;51: 23-47.

27 Kreek MJ, Raghunath J, Plevy S, Hamer D, Schneider B, Hartmann N: ACTH, cortisol and $\beta$-endorphin response to metyrapone testing during chronic methadone maintenance treatment in humans. Neuropeptides 1984;5:277-278.

28 Cushman Jr P, Kreek MJ: Some endocrinological observations in narcotic addicts; in Zimmerman E, George R (eds): Narcotics and the Hypothalamus. New York, Raven Press, 1974, pp 161-173.

29 Kreek MJ, Hartman N: Chronic use of opioids and antipsychotic drugs: side effects, effects on endogenous opioids, and toxicity. Ann NY Acad Sci 1982;398:151-172.

30 Walter M, Wiesbeck GA, Bloch N, Aeschbach S, Olbrich HM, Seifritz E, DürstelerMacFarland KM: Psychobiological responses to drug cues before and after methadone intake in heroin dependent patients: a pilot study. Eur Neuropsychopharmacol 2008;18: 390-393.

31 Walter M, Wiesbeck GA, Degen B, Albrich J, Oppel M, Schulz A, Schächinger H, Dürsteler-MacFarland KM: Heroin reduces startle and cortisol response in opioid-maintained heroin-dependent patients. Addict Biol 2011; 16:145-151.
32 Uchtenhagen A: Heroin-assisted treatment in Switzerland: a case study in policy change. Addiction 2010;105:29-37.

-33 Rehm J, Gschwend P, Steffen T, Gutzwiller F, Dobler-Mikola A, Uchtenhagen A: Feasibility, safety, and efficacy of injectable heroin prescription for refractory opioid addicts: a follow-up study. Lancet 2001;358:14171420

34 Dürsteler-MacFarland KM, Stohler R, Moldovanyi A, Rey S, Basdekis R, Gschwend P, Eschmann S, Rehm J: Complaints of heroinmaintained patients: a survey of symptoms ascribed to diacetylmorphine. Drug Alcohol Depend 2006;81:231-239.

35 Oviedo-Joekes E, Brissette S, Marsh DC, Lauzon P, Guh D, Anis A, Schechter MT: Diacetylmorphine versus methadone for the treatment of opioid addiction. N Engl J Med 2009;361:777-786.

36 van den Brink W, Hendricks VM, Blanken P, Koeter MWJ, van Zwieten BJ, van Ree JM: Medical prescription of heroin to treatment resistant heroin addicts: two randomised controlled trials. BMJ 2003;327:310.

-37 Blanken P, Hendriks VM, Koeter MVJ, van Ree JM, van den Brink W: Matching of treatment resistant heroin-dependent patients to medical prescription of heroin or oral methadone treatment: results from two randomized controlled trials. Addiction 2005; 100: 89-95.

38 Haasen C, Verthein U, Degkwitz P, Berger J, Krausz M, Naber D: Heroin-assisted treatment for opioid dependence. Randomized controlled trial. Br J Psychiatry 2007;191:5562.

39 Verthein U, Bonorden-Kleij K, Degwitz P, Dilg C, Köhler WK, Passie T, Soyka M, Tanger S, Vogel M, Haasen C: Long-term effects of heroin-assisted treatment in Germany. Addiction 2008;103:960-966.

40 Tiffany ST, Fields L, Singleton E, Haertzen C, Henningfield JE: The development of a heroin craving questionnaire. Purdue University, 1993, unpublished manuscript.

41 Stitzer ML, Sigmon SC: Other substance use disorders: prevalence, consequences, detection and management; in Strain EC, Stitzer ML (eds): The Treatment of Opioid Dependence. Baltimore, John Hopkins University Press, 2006, pp 365-397.

-42 Kirschbaum C, Pierke KM, Hellhammer DH: The 'Trier Social Stress Test' - a tool for investigating psychobiological stress responses in a laboratory setting. Neuropsychobiology 1993;28:76-81.

43 Dickerson SS, Kemeny ME: Acute stressors and cortisol responses: a theoretical integration and synthesis of laboratory research. Psychol Bull 2004;130:355-391.

-44 Tessner KD, Walker EF, Hochman K, Hamann S: Cortisol responses of healthy volunteers undergoing magnetic resonance imaging. Hum Brain Mapp 2006;27:889-895. 
-45 Peters S, Cleare AJ, Papadopoulos A, Fu CHY: Cortisol responses to serial MRI scans in healthy adults and in depression. Psychoneuroendocrinology 2011;36:737-741.

-46 Muehlhan M, Lueken U, Wittchen HU, Kirschbaum C: The scanner as a stressor: evidence from subjective and neuroendocrine stress parameters in the time course of a functional magnetic resonance imaging session. Int J Psychophysiol 2011;79:118-126.

-47 Walter M, Gerhard U, Duersteler-MacFarland KM, Weijers H-G, Boening J, Wiesbeck GA: Social factors but not stress-coping styles predict relapse in detoxified alcoholics. Neuropsychobiology 2006;54:100-106.
48 Sinha R, Garcia M, Paliwal P, Kreek MJ, Rounsaville BJ: Stress-induced cocaine craving and hypothalamic-pituitary-adrenal responses are predictive of cocaine relapse outcome. Arch Gen Psychiatry 2006;63:324331.

49 Stohler R, Dürsteler KM, Störmer R, Seifritz E, Hug I, Sattler-Mayr J, Müller-Spahn F, Ladewig D, Hock C: Rapid cortical hemoglobin deoxygenation after heroin and methadone injection in humans: a preliminary report. Drug Alcohol Depend 1999;57:23-28.
50 Frick U, Rehm J, Zullino D, Fernando M, Wiesbeck G, Amman J, Uchtenhagen A: Long-term follow-up of orally administered diacetylmorphine substitution treatment. Eur Addict Res 2010;16:131-138.

51 Gerber H, Borgwardt SJ, Gerhard U, Riecher-Rössler A, Wiesbeck GA, Walter M: Stress und Stressreaktivität bei der Opioidabhängigkeit. Ein Überblick (Stress and stress reactivity in opioid dependence). Schweiz Arch Neurol 2011;162:239-245.

52 Haasen C, Verthein U, Eiroa-Orosa FJ, Schäfer I, Reimer J: Is heroin-assisted treatment effective for patients with no previous maintenance treatment? Results from a German randomised controlled trial. Eur Addict Res 2010;16:124-130. 